\title{
Modulation of peritoneal macrophage activity by the saturation state of the fatty acid moiety of phosphatidylcholine
}

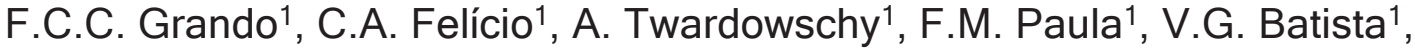 \\ L.C. Fernandes ${ }^{1}$, R. Curi $^{2}$ and A. Nishiyama ${ }^{1}$ \\ ${ }^{1}$ Departamento de Fisiologia, Universidade Federal do Paraná, Curitiba, PR, Brasil \\ ${ }^{2}$ Departamento de Fisiologia e Biofísica, Universidade de São Paulo, São Paulo, SP, Brasil
}

Correspondence to: A. Nishiyama, Departamento de Fisiologia, Setor de Ciências Biológicas, Centro

Politécnico, Universidade Federal do Paraná, 81531-990 Curitiba, PR, Brasil

Fax: +55-41-3361-1714. E-mail: anita.nishi@ufpr.br

\begin{abstract}
To determine the effects of saturated and unsaturated fatty acids in phosphatidylcholine (PC) on macrophage activity, peritoneal lavage cells were cultured in the presence of phosphatidylcholine rich in saturated or unsaturated fatty acids (sat PC and unsat $\mathrm{PC}$, respectively), both used at concentrations of 32 and $64 \mu \mathrm{M}$. The treatment of peritoneal macrophages with $64 \mu \mathrm{M}$ unsat PC increased the production of hydrogen peroxide by $48.3 \%$ compared to control $(148.3 \pm 16.3$ vs $100.0 \pm 1.8 \%, N=15)$, and both doses of unsat PC increased adhesion capacity by nearly $50 \%$. Moreover, $64 \mu \mathrm{M}$ unsat PC decreased neutral red uptake by lysosomes by $32.5 \%$ compared to the untreated group (67.5 \pm 6.8 vs $100.0 \pm 5.5 \%, N=15)$, while both 32 and $64 \mu \mathrm{M}$ unsat PC decreased the production of lipopolysaccharide-elicited nitric oxide by $30.4 \%$ (13.5 \pm 2.6 vs $19.4 \pm 2.5 \mu \mathrm{M})$ and $46.4 \%$ (10.4 \pm 3.1 vs $19.4 \pm 2.5 \mu \mathrm{M})$, respectively. Unsat PC did not affect anion production in non-stimulated cells or phagocytosis of unopsonized zymosan particles. A different result pattern was obtained for macrophages treated with sat PC. Phorbol 12miristate 13-acetate-elicited superoxide production and neutral red uptake were decreased by nearly $25 \%$ by 32 and $64 \mu \mathrm{M}$ sat PC, respectively. Sat PC did not affect nitric oxide or hydrogen peroxide production, adhesion capacity or zymosan phagocytosis. Thus, PC modifies macrophage activity, but this effect depends on cell activation state, fatty acid saturation and esterification to PC molecule and PC concentration. Taken together, these results indicate that the fatty acid moiety of PC modulates macrophage activity and, consequently, is likely to affect immune system regulation in vivo.
\end{abstract}

Key words: Phosphatidylcholine; Lecithin; Macrophages; Fatty acids; Reactive oxygen species; Phagocytosis

Research supported by Fundação Araucária. Publication supported by FAPESP.

Received September 1, 2008. Accepted March 27, 2009

\section{Introduction}

Phosphatidylcholine (PC) is the main component of biological membranes. It plays an important role in signal transduction and in the generation of bioactive molecules. The hydrolysis of PC produces fatty acids, prostaglandins, platelet-activating factors, and diacylglycerols $(1,2)$, which participate in inter- and intracellular signaling and affect macrophage response to a wide range of stimuli. Thus, the incorporation of different fatty acids into PC by peritoneal macrophages may be an important pathway for the alteration of macrophage activity. If the physiological properties of a variety of cell types can be modified by exposing them to different lipid classes (3-5), it is reasonable to assume that PC incorporation into membranes could also lead to significant alterations in macrophage activities. Previous studies have shown that peritoneal macrophages actively take up PC in vitro (6). The physiological consequences of this process for peritoneal macrophages are unclear, but some studies have reported that saturated phospholipids 
compromise alveolar macrophage activity (7). In the lung, macrophages internalize surfactant lipids (8), a process that reduces phagocytic capacity and the production of reactive oxygen species (ROS) (9-11).

PC containing unsaturated fatty acids may also modify macrophage activity. It has been demonstrated that large amounts of PC containing arachidonic acid are found in rat peritoneal macrophages (12). The activity of desaturases and elongases on linoleic acid generates arachidonic acid, which is the precursor of prostaglandins, thromboxanes and leukotrienes. These molecules play important roles in the regulation of the inflammatory response (4). Polyunsaturated fatty acids are involved in the expression of adhesion molecules and ROS production (13). Additionally, arachidonic acid is formed in response to many agonists, such as calcium ionophore, phorbol 12-miristate 13acetate (PMA) and bacterial lipopolysacharide (LPS) (14). Arachidonic acid produced by the activation of cytosolic phospholipase $A_{2}$ stimulates NADPH oxidase, which is associated with the production of $\operatorname{ROS}(15,16)$. Therefore, the availability of intracellular fatty acids may affect important macrophage activity, such as phagocytosis capacity, adhesion property and the production of reactive oxygen and nitrogen species, and this effect depends on the activation state of the cell.

Despite the importance of phospholipids as a source of bioactive molecules, there are no known studies about the direct effects of the nature of the fatty acid component of PC on peritoneal macrophage activity. In the present study, we hypothesized that macrophage activity is modulated by the molecular species of saturated and unsaturated fatty acid-rich PC. We carried out an in vitro experiment with rat peritoneal macrophages and evaluated the alterations in their adhesion, neutral red (NR) uptake by lysosomes, and production of ROS and nitric oxide (NO).

\section{Material and Methods}

\section{Chemicals}

Distearoylphosphatidylcholine (sat PC) was obtained from Avanti Polar Lipids (USA) and linoleic acid-rich PC (unsat PC) from soybean was obtained from Sigma (USA). Cell culture medium (RPMI-1640), penicillin, streptomycin, and fetal calf serum (FCS) were obtained from Cultilab (Brazil). Horseradish peroxidase, E. coli LPS, PMA, phenol red, nitroblue tetrazolium (NBT), NR, and other reagents were obtained from Sigma.

\section{Animals \\ Male Wistar rats weighing $200 \pm 20 \mathrm{~g}$ were provided by the Setor de Ciências Biológicas, Universidade Federal do}

Paraná (Curitiba, PR, Brazil). All procedures were in accordance with the guidelines for animal experimentation, and the practices were approved by the institutional Animal Ethics Committee.

\section{Peritoneal cell preparation}

Resident macrophages were obtained from the peritoneal cavity by injection of phosphate-buffered solution (PBS). Cells were washed twice in PBS and suspended in RPMI-1640 medium containing 10\% FCS, 10,000 U/mL penicillin G sodium, $10 \mathrm{mg} / \mathrm{mL}$ streptomycin sulfate, and 2 $\mathrm{mM}$ glutamine. FCS was inactivated for $30 \mathrm{~min}$ at $56^{\circ} \mathrm{C}$. The macrophages suspended in culture medium were preincubated in 96 -well microplates for $40 \mathrm{~min}$ at $37^{\circ} \mathrm{C}$ in a moist atmosphere of $5 \% \mathrm{CO}_{2}$. This process promoted macrophage adherence to the plate. Nonadherent cells were removed by washing the plate twice with PBS.

\section{Phosphatidylcholine medium preparation}

A thin film of PC dissolved in chloroform was allowed to dry spontaneously under sterile conditions. Phospholipids were hydrated with RPMI-1640 medium containing $10 \%$ FCS and then sonicated for $15-20 \mathrm{~min}$. The PC solution was dissolved to reach final concentrations of 32 and $64 \mu \mathrm{M}$.

\section{Determination of phosphatidylcholine cytotoxicity}

After treatment with sat PC and unsat PC, the 3-(4,5dimethyl-2-thiazolyl)-2,5-diphenyl tetrazolium bromide (MTT) assay was performed (17). Cells $\left(5 \times 10^{5}\right)$ were cultured on 96-well plates with or without PC. After 2 or 24 $\mathrm{h}, 10 \mu \mathrm{L} 10 \mathrm{mg} / \mathrm{mL}$ MTT solution was added to each well. After $2 \mathrm{~h}$ of incubation at $37^{\circ} \mathrm{C}$, the formazan produced was solubilized with dimethylsulfoxide and the absorbance of the formazan solution was measured with a microplate reader at $570 \mathrm{~nm}$ (Bio-Rad, USA).

\section{Nitrite determination}

NO was estimated from nitrite levels, as described by Stuehr and Marletta (18). Cells ( 2 × 105/well) were stimulated with LPS $(10 \mu \mathrm{g} / \mathrm{mL})$ in the presence of PC for $24 \mathrm{~h}$. After this period, $100 \mu \mathrm{L}$ of culture supernatant was mixed with the same volume of Griess reagent ( $1 \%$ sulfanilamide in $5 \% \mathrm{H}_{3} \mathrm{PO}_{4}$ and $0.1 \% \mathrm{~N}$-(1-naphthyl) ethylenediamine dihydrochloride, in water) and absorbance was determined at $550 \mathrm{~nm}$ with a microplate reader.

\section{Hydrogen peroxide determination}

The production of hydrogen peroxide was measured according to the protocol described by Pick and Mizel (19). Adhered macrophages ( $5 \times 10^{5} /$ well) were cultured for $2 \mathrm{~h}$ 
with PC. After this period, cells were stimulated with PMA ( $200 \mathrm{nM}$ ) when indicated. After $1 \mathrm{~h}$ of incubation, a solution of phenol red and horseradish peroxidase was added to the medium to estimate hydrogen peroxide content. After $10 \mathrm{~min}, 10 \mu \mathrm{L} 1 \mathrm{M} \mathrm{NaOH}$ solution was added to adjust $\mathrm{pH}$ to alkalinity and the amount of hydrogen peroxide formed was measured spectrophotometrically at $610 \mathrm{~nm}$.

\section{Nitroblue tetrazolium reduction assay}

Intracellular generation of superoxide anion was measured by NBT reduction (20). Adhered macrophages ( 5 x $10^{5}$ / well) were cultured for $2 \mathrm{~h}$ with PC. After this period, cells were stimulated with $200 \mathrm{nM}$ PMA in the presence of $0.1 \%$ NBT for $1 \mathrm{~h}$. The cells were then washed twice by centrifugation at $800 \mathrm{~g}$ for $5 \mathrm{~min}$ with PBS, fixed with $50 \%$ methanol for $10 \mathrm{~min}$ and air-dried. The reaction product (formazan) was solubilized by 30 -min incubation in $120 \mu \mathrm{L} 2 \mathrm{M}$ potassium hydroxide and $140 \mu \mathrm{L}$ dimethylsulfoxide per well. The plates were read spectrophotometrically at $490 \mathrm{~nm}$.

\section{Neutral red assay}

The uptake of the cationic dye NR, which is concentrated in macrophage lysosomes, was evaluated (21). The adhered macrophages were cultivated for $2 \mathrm{~h}$ with PC. Cells were treated with $20 \mu \mathrm{L} 3 \%$ NR in PBS and washed twice with PBS and the internalized NR was solubilized for 30 -min incubation by adding $0.1 \mathrm{~mL} 10 \%$ acetic acid plus $40 \%$ ethanol solution. Absorbance was determined at $550 \mathrm{~nm}$.

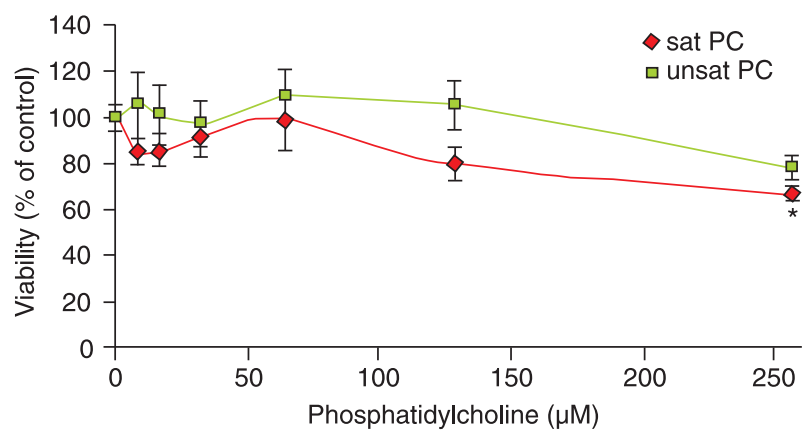

Figure 1. Effect of distearoylphosphatidylcholine (sat PC) and linoleic acid-rich $P C$ (unsat $P C$ ) on macrophage viability determined by the 3-(4,5-dimethyl-2-thiazolyl)-2,5-diphenyl tetrazolium bromide (MTT) assay. Sat PC and unsat PC were added to the macrophage culture at concentrations up to $256 \mu \mathrm{M}$ for $24 \mathrm{~h}$. After this period, MTT solution was added to each well. The reaction product was solubilized and the absorbance was measured at $570 \mathrm{~nm}$. Data are reported as percent of control \pm SEM, and represent the mean of $\mathrm{N}=30$. ${ }^{*} \mathrm{P}<0.05$ vs untreated group (ANOVA)

\section{Macrophage phagocytosis}

Macrophages $\left(2 \times 10^{5}\right.$ cells/well) were cultured for $24 \mathrm{~h}$ in the presence of $\mathrm{PC}$ and then incubated with NR-stained zymosan (21). After 30-min incubation, the supernatant was removed and Baker's formol-calcium solution was added to stop zymosan phagocytosis. The cells were washed by centrifugation in PBS. After NR solubilization with acidified alcohol, absorbance was determined spectrophotometrically at $550 \mathrm{~nm}$.

\section{Macrophage adhesion assay}

Macrophage adhesion was assayed according to the procedure described by Rosen and Gordon (22). Peritoneal wash cells $\left(4 \times 10^{5}\right.$ cells/well) were cultured for $24 \mathrm{~h}$ in a medium containing PC. After incubation, the plates were washed three times with PBS and the adherent cells were fixed with methanol. After staining with $10 \%$ Giemsa solution for $10 \mathrm{~min}$, the plates were washed with water, and the remaining dye was solubilized with methanol. Absorbance was determined spectrophotometrically at $550 \mathrm{~nm}$.

\section{Statistical analysis}

Data are reported as means \pm SEM. Statistical differences between groups were determined by one-way analysis of variance $(P<0.05$, ANOVA). All experiments were carried out in quadruplicate and repeated at least three times.

\section{Results}

To study the effect of the nature of the fatty acid PC on macrophage viability, various concentrations were tested. As illustrated in Figure 1, macrophages incubated for $24 \mathrm{~h}$ with $256 \mu \mathrm{M}$ of sat PC (distearoylphosphatidylcholine) suffered a significant decrease in cell viability. Thus, concentrations below $256 \mu \mathrm{M}$ were used in the experiments.

\section{Respiratory burst}

The effects of the PC fatty acid moiety on NO formation by peritoneal macrophages were determined (Figure 2). Incubation of LPS-stimulated macrophages with unsat PC decreased NO production in a dose-dependent manner. Nitrite levels decreased by $30.4 \%$ compared to the control group $(13.5 \pm 2.6$ vs $19.4 \pm 2.5 \mu \mathrm{M})$ with $32 \mu \mathrm{M}$ unsat $\mathrm{PC}$ treatment and by $46.4 \%(10.4 \pm 3.1$ vs $19.4 \pm 2.5 \mu \mathrm{M}, \mathrm{N}=$ $15)$ in $64 \mu \mathrm{M}$ unsat PC treatment. Sat PC did not affect LPS-stimulated and -non-stimulated macrophages.

Superoxide production in PMA-stimulated macrophages increased markedly (Figure 3). However, this was not observed when these macrophages were treated with sat 

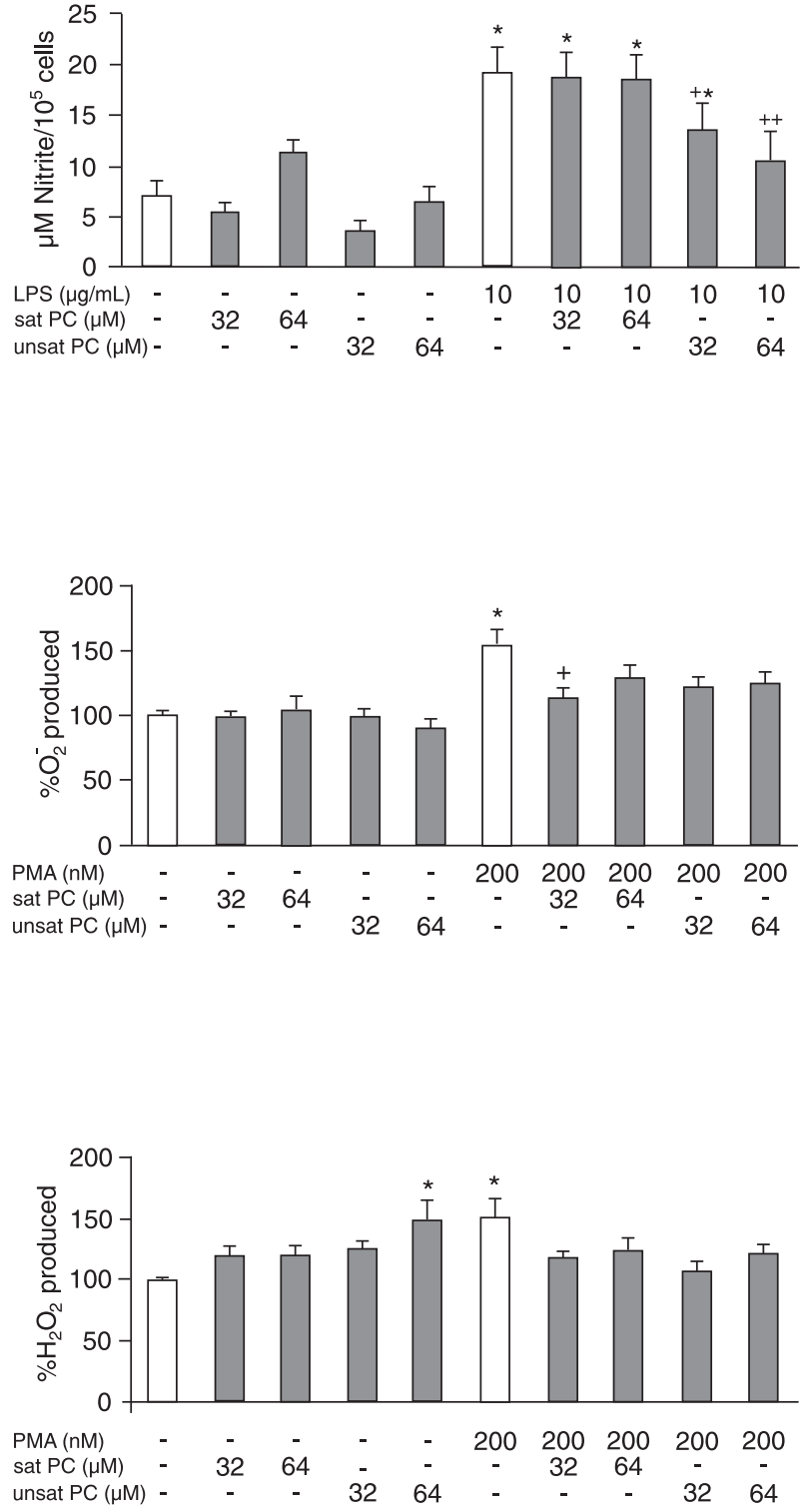

PC or unsat PC. In spite of this, incubation with $32 \mu \mathrm{M}$ sat PC inhibited $26.1 \%(113.7 \pm 7.0$ vs $153.9 \pm 12.0 \%, N=15)$ of NBT reduction by stimulated macrophages.

Hydrogen peroxide production was enhanced by $51.4 \%$ $(151.4 \pm 15.5$ vs $100.0 \pm 1.8 \%, N=15)$ in PMA-stimulated macrophages (Figure 4). The treatment with $64 \mu \mathrm{M}$ unsat PC under non-stimulated conditions increased hydrogen peroxide production by $48.3 \%(148.3 \pm 16.3$ vs $100.0 \pm$ $1.8 \%, N=15)$. Incubation with sat PC did not affect hydrogen peroxide production, irrespective of the nonstimulated condition or the presence of PMA.
Figure 2. Nitrite production by peritoneal macrophages treated with distearoylphosphatidylcholine (sat PC) and linoleic acid-rich PC (unsat PC) at concentrations of 32 and $64 \mu \mathrm{M}$. Cells were incubated with or without lipopolysaccharide (LPS) $(10 \mu \mathrm{g} / \mathrm{mL})$ for $24 \mathrm{~h}$ at $37^{\circ} \mathrm{C}$. After this period, cell-free culture media were mixed with Griess reagent. The concentration of nitrite was determined spectrophotometrically, using a sodium nitrite standard curve. Data are reported as mean concentration \pm SEM, and represent the mean of $\mathrm{N}=15$. ${ }^{*} \mathrm{P}<0.01$ vs untreated group. ${ }^{+} \mathrm{P}<$ 0.05 vs LPS-treated group; ${ }^{++} \mathrm{P}<0.001$ vs LPS-treated group (ANOVA).

Figure 3. Nitroblue tetrazolium (NBT) reduction by phosphatidylcholine (PC)-treated macrophages. Cells were incubated with distearoylphosphatidylcholine (sat PC) and linoleic acid-rich PC (unsat PC) at concentrations of 32 and $64 \mu \mathrm{M}$ for $2 \mathrm{~h}$. After this period, macrophages were cultured with $200 \mathrm{nM}$ phorbol 12miristate 13-acetate (PMA) and $0.1 \%$ NBT for $1 \mathrm{~h}$. The reaction product was solubilized and the plates were read spectrophotometrically at $490 \mathrm{nM}$. Data are reported as percent of control \pm SEM, and represent the mean of $N=15$. ${ }^{*} P<0.001$ vs untreated group; ${ }^{+} \mathrm{P}<0.05$ vs $\mathrm{PMA}-$ stimulated group (ANOVA).

Figure 4. Effect of phosphatidylcholine (PC) on hydrogen peroxide production. Macrophages were incubated with distearoylphosphatidylcholine (sat PC) and linoleic acid-rich PC (unsat $\mathrm{PC}$ ) at concentrations of 32 and $64 \mu \mathrm{M}$. After this period, cells were cultured with $200 \mathrm{nM}$ phorbol 12-miristate 13-acetate (PMA) for $1 \mathrm{~h}$. Data are reported as percent of control \pm SEM, and represent the mean of $\mathrm{N}=15$. ${ }^{*} \mathrm{P}<0.05$ vs untreated group (ANOVA).

Phagocytosis, adhesion and neutral red uptake

Treatment with different species of PC did not affect the phagocytic activity of peritoneal macrophages (data not shown). However, in the treatments with $64 \mu \mathrm{M} \mathrm{PC}, \mathrm{NR}$ uptake decreased by $24.8 \%$ (75.24 \pm 7.2 vs $100.0 \pm 5.5 \%)$ in the sat PC group and $32.5 \%$ ( $67.5 \pm 6.8$ vs $100.0 \pm 5.5 \%$, $\mathrm{N}=15$ ) in the unsat $\mathrm{PC}$ group (Figure 5).

The addition of unsat PC stimulated adhesion (Figure 6). The $32 \mu \mathrm{M}$ concentration increased adhesion by $53.6 \%$ $(0.278 \pm 0.015$ vs $0.181 \pm 0.016)$, whereas $64 \mu \mathrm{M}$ increased it by $50.8 \%(0.273 \pm 0.014$ vs $0.181 \pm 0.016, N=15)$. 

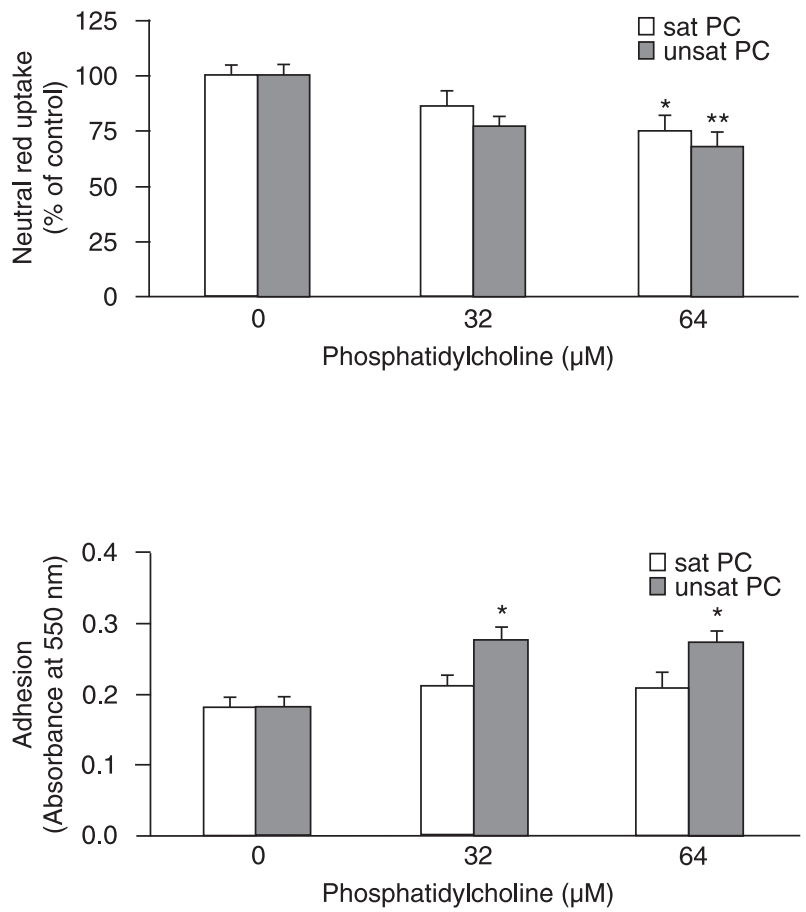

\section{Discussion}

The present study shows that the effects of PC on macrophage activity depend on the nature of the fatty acid esterified in its glycerol backbone. The nature of the fatty acid within membrane phospholipids indeed contributes to membrane fluidity and is likely to play a role in the regulation of membrane protein activity (23). Therefore, the effect of PC fatty acids may affect the activation of inflammatory cells such as macrophages. In addition, membrane phospholipids are also the source of second messenger molecules, such as diacylglycerol, phosphatidic acid, inositol1,4,5-triphosphate, ceramide, and arachidonic acid. These molecules signal events originating in the membrane to the cytosol and to the nucleus, eliciting appropriate cell responses (23).

Macrophages are multifunctional cells that play an important role in immune responses. The activation of these cells promotes the expression of genes that induce the high-output synthesis of reactive oxygen and nitrogen species (24). NO production is catalyzed by inducible nitric oxide synthase, and its activity in the macrophage is first regulated and modulated by cell receptors such as Tolllike receptors and CD14. CD14 is the receptor for LPS and plays an essential role in proinflammatory responses in
Figure 5. Effects of phosphatidylcholine (PC) on neutral red uptake into macrophage lysosomes. Macrophages were cultured for $2 \mathrm{~h}$ with distearoylphosphatidylcholine (sat $\mathrm{PC}$ ) and linoleic acid-rich PC (unsat PC) at concentrations of 32 and 64 $\mu \mathrm{M}$. Cells were analyzed spectrophotometrically for their content of neutral red, solubilized with acid solution. Data are reported as percent of control \pm SEM, and represent the mean of $N=15$. ${ }^{*} \mathrm{P}$ $<0.05$ vs untreated group; ${ }^{* *} \mathrm{P}<0.01$ vs untreated group (ANOVA)

Figure 6. Effects of phosphatidylcholine (PC) species on macrophage adhesion. Peritoneal cells were incubated with distearoylphosphatidylcholine (sat PC) and linoleic acid-rich PC (unsat $\mathrm{PC}$ ) at concentrations of 32 and $64 \mu \mathrm{M}$. After $24 \mathrm{~h}$, macrophages were stained with $10 \%$ Giemsa. Data are reported as absorbance \pm SEM, and represent the mean of $N=15$. ${ }^{*} P<0.01$ vs control group (ANOVA).

monocytes and macrophages via activation of the NFKB pathway (25). The data presented here demonstrate that $\mathrm{PC}$ containing unsaturated fatty acids have an inhibitory effect on NO production by LPS-activated macrophages. This treatment was associated with a dose-dependent decrease in NO production and this result suggests that unsat PC may affect the NFKB pathway.

The inhibitory effect on NO production was not due to a loss of membrane integrity, since macrophage viability was not different from the control group, as assessed by the MTT reduction assay. The cells cultured for $2 \mathrm{~h}$ at any of the PC concentrations tested preserved cell viability (data not shown). However, after $24 \mathrm{~h}$ of culture, macrophage viability decreased at doses above $256 \mu \mathrm{M}$ sat PC. We were concerned about a possible toxic effect of $P C$ at the concentrations used in the experiments, but the cell culture assay enabled us to differentiate it. Although many other parameters may be involved, this study provides evidence of the cytotoxic effect of PC at high concentrations, which contributes to down-regulating the inflammatory responses.

An additional, prominent characteristic of activated macrophages is their high capacity to release superoxide and hydrogen peroxides (26). The enzyme complex primarily responsible for producing superoxide anion is the 
NADPH oxidase complex, which can be activated directly through the activation of protein kinase $\mathrm{C}$ by phorbol esters (27). This suggests that protein kinase $C$ can be a major mediator of NADPH oxidase activation (28). When the macrophages were stimulated with PMA, superoxide anion production was notably enhanced. However, the treatment of these cells with sat PC in the presence of PMA decreased superoxide anion production, suggesting that $\mathrm{PC}$ is involved in this pathway.

The superoxide anion is converted to hydrogen peroxide by superoxide dismutase. When unstimulated macrophages were treated with unsat $P C$, there was a significant increase in hydrogen peroxide production, which shows that unsat PC were capable of activating macrophages. On the other hand, sat PC inhibited hydrogen peroxide production by activated macrophages, suggesting that complex mechanisms are used according to cell activation state. The present study showed that PC affected the macrophage production of ROS, which aids in the destruction of antigens and contributes to increasing oxidative stress (26). These results indicate that PC is the modulator of another pathway, i.e., the pathway for ROS production.

ROS production is associated with other events such as phagocytosis and microparticle digestion. In the present study, PC did not modify the phagocytic capacity of macrophages (data not shown). However, the NR uptake assay detected a decrease in lysosome volume for both PC species. Whereas these lipids reduced the degradative mechanism of phagocytic cells, unsat PC increased their adhesion capacity. Considering that this process

\section{References}

1. Zhang F, Zhao G, Dong Z. Phosphatidylcholine-specific phospholipase $C$ and D in stimulation of RAW264.7 mouse macrophage-like cells by lipopolysaccharide. Int Immunopharmacol 2001; 1: 1375-1384.

2. Melendez AJ, Allen JM. Phospholipase D and immune receptor signalling. Semin Immunol 2002; 14: 49-55.

3. Vallve JC, Uliaque K, Girona J, Cabre A, Ribalta J, Heras M, et al. Unsaturated fatty acids and their oxidation products stimulate CD36 gene expression in human macrophages. Atherosclerosis 2002; 164: 45-56.

4. Calder PC. Polyunsaturated fatty acids, inflammation, and immunity. Lipids 2001; 36: 1007-1024.

5. Wallace FA, Neely SJ, Miles EA, Calder PC. Dietary fats affect macrophage-mediated cytotoxicity towards tumour cells. Immunol Cell Biol 2000; 78: 40-48.

6. Nishiyama-Naruke A, Curi R. Phosphatidylcholine participates in the interaction between macrophages and lymphocytes. Am J Physiol Cell Physiol 2000; 278: C554-C560.

7. Golioto A, Wright JR. Effects of surfactant lipids and surfac- requires the arrangement of significant amounts of membrane, PC incorporation by macrophages probably modified adhesion capacity by altering membrane fluidity, as shown in an earlier study (6).

On the basis of the present results, we suggest that the complex effects of PC on macrophages are dependent on i) cell activation state, ii) fatty acid saturation and esterification to the PC molecule, PC concentration and incorporation time. There is evidence that omega- 6 polyunsaturated fatty acids (PUFAs) have both inhibitory and stimulatory effects on immune responses. The most widely studied PUFA is arachidonic acid, which can be oxidized to eicosanoids, potent mediators of inflammation. Nevertheless, many effects of the PUFAs on immune and inflammatory responses are not dependent on eicosanoid generation (13). Several mechanisms have been proposed, such as changes in membrane fluidity and in signal transduction pathways, regulation of gene transcription, protein acylation, and calcium release (13). Our results suggest that PC modulates macrophage functionality by altering its membrane fluidity. As previously shown (6), macrophages are capable of incorporating phosphatidylcholines, which change the unsaturation index and, as a consequence, affect fluidity. Additional research is needed to reveal the mechanisms by which PC changes macrophage activity. In vivo studies are also necessary to evaluate the physiological effects of PC. This information will be useful as a therapeutic tool to combat pathological conditions such as inflammatory processes. tant protein $\mathrm{A}$ on host defense functions of rat alveolar macrophages. Pediatr Res 2002; 51: 220-227.

8. Poelma DL, Zimmermann LJ, Scholten HH, Lachmann B, van Iwaarden JF. In vivo and in vitro uptake of surfactant lipids by alveolar type II cells and macrophages. Am J Physiol Lung Cell Mol Physiol 2002; 283: L648-L654.

9. Sano H, Kuroki Y. The lung collectins, SP-A and SP-D, modulate pulmonary innate immunity. Mol Immunol 2005; 42: 279-287.

10. Pinot F, Bachelet M, Francois D, Polla BS, Walti H. Modified natural porcine surfactant modulates tobacco smoke-induced stress response in human monocytes. Life Sci 1999; 64: 125-134.

11. Evora C, Soriano I, Rogers RA, Shakesheff KN, Hanes J, Langer R. Relating the phagocytosis of microparticles by alveolar macrophages to surface chemistry: the effect of 1,2-dipalmitoylphosphatidylcholine. J Control Release 1998; 51: 143-152.

12. Akoh CC, Chapkin RS. Composition of mouse peritoneal 
macrophage phospholipid molecular species. Lipids 1990; 25: 613-617.

13. Pompeia C, Lopes LR, Miyasaka CK, Procopio J, Sannomiya $\mathrm{P}$, Curi R. Effect of fatty acids on leukocyte function. Braz J Med Biol Res 2000; 33: 1255-1268.

14. Hiller G, Sternby M, Sundler R, Wijkander J. Phosphatidylinositol 3-kinase in zymosan- and bacteria-induced signalling to mobilisation of arachidonic acid in macrophages. Biochim Biophys Acta 2000; 1485: 163-172.

15. Pompeia C, Cury-Boaventura MF, Curi R. Arachidonic acid triggers an oxidative burst in leukocytes. Braz $J$ Med Biol Res 2003; 36: 1549-1560.

16. Brash AR. Arachidonic acid as a bioactive molecule. J Clin Invest 2001; 107: 1339-1345.

17. Mosmann T. Rapid colorimetric assay for cellular growth and survival: application to proliferation and cytotoxicity assays. J Immunol Methods 1983; 65: 55-63.

18. Stuehr DJ, Marletta MA. Mammalian nitrate biosynthesis: mouse macrophages produce nitrite and nitrate in response to Escherichia coli lipopolysaccharide. Proc Natl Acad Sci U S A 1985; 82: 7738-7742.

19. Pick E, Mizel D. Rapid microassays for the measurement of superoxide and hydrogen peroxide production by macrophages in culture using an automatic enzyme immunoassay reader. J Immunol Methods 1981; 46: 211-226.

20. Dyrynda EA, Pipe RK, Burt GR, Ratcliffe NA. Modulations in the immune defences of mussels (Mytilus edulis) from contaminated sites in the UK. Aquat Toxicol 1998; 42: 169-185.
21. Pipe RK, Coles JA, Farley SR. Assays for measuring immune response in the mussel Mytilus edulis. Tech Fish Immunol 1995; 4: 93-100.

22. Rosen H, Gordon S. Monoclonal antibody to the murine type 3 complement receptor inhibits adhesion of myelomonocytic cells in vitro and inflammatory cell recruitment in vivo. J Exp Med 1987; 166: 1685-1701.

23. Calder PC. Long-chain n-3 fatty acids and inflammation: potential application in surgical and trauma patients. Braz $J$ Med Biol Res 2003; 36: 433-446.

24. Bosca L, Zeini M, Traves PG, Hortelano S. Nitric oxide and cell viability in inflammatory cells: a role for $\mathrm{NO}$ in macrophage function and fate. Toxicology 2005; 208: 249-258.

25. Schroder NW, Opitz B, Lamping N, Michelsen KS, Zahringer $\mathrm{U}$, Gobel UB, et al. Involvement of lipopolysaccharide binding protein, CD14, and Toll-like receptors in the initiation of innate immune responses by Treponema glycolipids. $J$ Immunol 2000; 165: 2683-2693.

26. Babior BM. NADPH oxidase: an update. Blood 1999; 93: 1464-1476.

27. Segal AW, Jones OT. Reduction and subsequent oxidation of a cytochrome $b$ of human neutrophils after stimulation with phorbol myristate acetate. Biochem Biophys Res Commun 1979; 88: 130-134.

28. Dekker LV, Leitges M, Altschuler G, Mistry N, McDermott A, Roes J, et al. Protein kinase C-beta contributes to NADPH oxidase activation in neutrophils. Biochem J 2000; 347 (Part 1): $285-289$. 